\title{
ANÁLISE DAS IMPORTAÇÕES BRASILEIRAS COMO FATORES DE RISCO DE DIFUSÃO DA ENCEFALOPATIA ESPONGIFORME BOVINA NO PAÍS
}

\author{
D.L. Rodrigues ${ }^{1}$, I.R. de Barros Filho' ${ }^{2}$, J.F.G. Warth ${ }^{2}$, R.D. Ollhoff ${ }^{3 *}$
}

${ }^{1}$ Ministério da Agricultura, Pecuária e Abastecimento, Serviço de Saúde Animal da Superintendência Federal de Agricultura do Estado do Paraná, Rua José Veríssimo, 420, CEP 82820-000, Curitiba, PR, Brasil. E-mail: diego.rodrigues@agricultura.gov.br

\section{RESUMO}

Nesta pesquisa são apresentadas e analisadas as importações brasileiras de bovinos e seus produtos derivados que representam risco para a Encefalopatia Espongiforme Bovina (EEB) realizadas no período de 2002 a 2009, conforme protocolo da Organização Mundial da Saúde Animal (OIE), no intuito de identificar riscos potenciais nas mercadorias internalizadas. Para tanto, foram utilizados os dados de tipo, volume e origem das importações, taxas de incidência e classificação de risco da EEB dos países exportadores disponibilizados pelo Ministério do Desenvolvimento, Indústria e Comércio Exterior, Ministério da Agricultura, Pecuária e Abastecimento e pela OIE. Neste período foram importados 476 bovinos vivos de países que registraram a EEB (Canadá e EUA), $7.791 .295 \mathrm{~kg}$ de produtos destinados à alimentação animal dos EUA e $36.038 \mathrm{~kg}$ originários da Malásia. Também foram identificadas importações de produtos de origem bovina destinados ao consumo humano no período: $156.869 \mathrm{~kg}$ dos EUA, $1600 \mathrm{~kg}$ da Itália e $1 \mathrm{~kg}$ da Espanha e para fins farmacêuticos: $37.194 \mathrm{~kg}$ de pâncreas bovino dos EUA e mais $457.719 \mathrm{~kg}$ de glândulas de origem animal (sem definição de espécie) também provenientes dos EUA, as quais, segundo a OIE, devem ser consideradas na análise de risco de introdução do agente, apesar de suas respectivas finalidades. Foi possível concluir que as mercadorias importadas, apesar do potencial identificado, representaram baixo risco de introdução do agente no território nacional e que os volumes diminuíram gradativamente no período analisado.

PALAVRAS-CHAVE: EEB, importação, análise de risco, Brasil.

\section{ABSTRACT}

ANALYSISOF BRAZILIAN IMPORTS ASRISKFACTORSFORDISSEMINATIONOF BOVINE SPONGIFORM ENCEPHALOPATHY IN THE COUNTRY. This research presents and analyzes Brazilian importation of cattle and derivate products which represent a risk of bovine spongiform encephalopathy (BSE) during the period from 2002 to 2009, according to World Organization for Animal Health (OIE) protocol, in order to identify the potential risk of goods brought in from abroad. The study considered data on the type, volume and origin of the imports, incident rates and BSE risk classification of exporting countries provided by the Brazilian Ministry of Development, Industry and Foreign Trade, the Ministry of Agriculture Livestock and Supply, and the OIE. Importations during this period included 496 cattle imported from countries which reported BSE (Canada and USA), 7,791,295 $\mathrm{kg}$ of products intended for animal feed from the USA, and 36,038 $\mathrm{kg}$ from Malaysia. The information available does not permit identification of the products' composition (species of origin), however according to the legislation prevailing during the period in question, the imports made between 2002 and 2007 represented a risk of presence of bovine protein. Also identified were imports of beef products intended for human consumption during that period $156.869 \mathrm{~kg}$ from USA; $1,600 \mathrm{~kg}$ from italy and $1 \mathrm{~kg}$ from spain. in addition for pharmaceutical use it was identified $37,194 \mathrm{~kg}$ of bovine pancreas from usa and 457,719 kg of glands from animals (undefined species) also from USA. It was possible to conclude that the imported goods despite the identified potential represented low risk of introduction of the infectious agent on the country and the volumes decreased gradually during that period.

KEY WORDS: BSE, importation, risk analysis, Brazil.

${ }^{2}$ Universidade Federal do Paraná, Setor de Ciências Agrárias, Departamento de Medicina Veterinária, Curitiba, PR, Brasil. ${ }^{4}$ Pontifícia Universidade Católica do Paraná, Curitiba, PR, Brasil.

*Programa de Pós-Graduação em Ciência Animal. 


\section{INTRODUÇÃO}

A Encefalopatia Espongiforme Bovina (EEB) é uma enfermidade neurodegenerativa progressiva e fatal, provocada por uma proteína alterada, descrita na década de 80 (Wells et al., 1987), tendo sido registrados mais de 190.000 casos da doença (OIE, 2011), altamente concentrados no Reino Unido, e cuja incidência foi reduzida drasticamente na última década, após adoção de medidas restritivas na alimentação de bovinos.

A epidemiologia é complexa por diferir do padrão de contágio de doenças infectocontagiosas. $\mathrm{O}$ principal fator relacionado é o consumo de proteína de origem ruminante pelo uso de farinhas de carne e ossos (WiLEsmith et al., 1988) e os tecidos envolvidos são aqueles provenientes do SNC e órgãos linfoides (Prince et al., 2003), embora somente sangue, sêmen, leite, couro, peles, gelatina, colágeno, sebo e músculo esquelético desossado sejam declarados como não veiculadores do príon (OIE, 2011).

Devido à associação da enfermidade em animais com o surgimento da nova variante da Doença de Creutzfeuldt-Jacob (nvDCJ) em seres humanos (WILL; IRONSIDE, 1996), a EEB tornou-se uma das enfermidades mais relevantes no contexto do comércio de bovinos e produtos derivados desta espécie.

O Brasil é considerado grande exportador de produtos agropecuários e, em relação à carne bovina, o volume de exportações é da ordem de 1,24 milhão de toneladas ao ano, equivalentes a US $\$ 4,7$ bilhões e tem disputado com a Austrália o posto de maior exportador do produto (BRASIL, 2011), que demonstra a relevância de manter um alto nível de excelência em sanidade animal. Neste sentido, a avaliação de risco da EEB é fundamental, pois, no contexto atual, a presença da doença e uma classificação de risco insatisfatória são importantes limitantes comerciais.

A análise de risco para a EEB compreende as importações de bovinos e produtos com potencial de introduzir o agente da EEB no território nacional (risco de difusão) e as medidas de mitigação, que visam impedir a reciclagem do agente, caso este seja introduzido em uma dada área (risco de exposição).

Nesteartigoédiscutidoespecificamente o risco de difusão do agente no Brasil por meio da apresentação e análise dos dados das importações brasileiras que, segundo as normas internacionais estabelecidas pelo Código Sanitário dos Animais Terrestres da Organização Mundial deSaúde Animal (OIE) (OIE, 2011), podem representar risco de introdução do agente.

\section{MATERIAL E MÉTODOS}

Para a discussão dos fatores relativos à difusão do agente foram utilizados os dados referentes às importações brasileiras de bovinos e demais mercadorias relacionadas à EEB, por país de origem, durante o período relevante indicado pela OIE (8 anos para produtos destinados à alimentação animal e sete anos para os demais) e seguindo as orientações estabelecidas pelo Código Sanitário para os Animais Terrestres (OIE, 2011).

Os dados ora analisados foram obtidos do Ministério do Desenvolvimento, Indústria e Comércio Exterior (MDIC) brasileiro, por meio da plataforma do Sistema de Análise de Informações de Comércio Exterior via Internet (Aliceweb), disponível no site eletrônico da instituição (BRASIL, 2010). Também foram utilizadas as informações de incidência mundial da doença divulgadas pela OIE, visando estabelecer o status sanitário dos países exportadores.

Os dados comerciais foram submetidos à matriz decisória, que considera o tipo de produto importado e o seu país de origem e o prolongado período de incubação da EEB na análise dos dados, que tornou possível detectar se foram realizadas importações com risco relevante. A referida matriz é baseada na legislação brasileira (BRASIL, 2008) e nas diretrizes da OIE sobre análise de risco (OIE, 2011).

Assim, foram selecionadas as importações de bovinos vivos e produtos derivados de países de risco. Para o tipo de mercadoria foram excluídos: leite e derivados, sêmen e embriões, couros e peles, gelatina e colágeno, sebo, carne de músculo esquelético desossada e sangue e derivados, conforme o Código Sanitário dos Animais Terrestres (OIE, 2011).

Ao considerar a origem da mercadoria, os países de risco são aqueles que relataram a doença em seus territórios até cinco anos após as importações, considerando assim o período de incubação da doença (WILESMith et al., 1988). Sobre estas análises, foi também aplicada a classificação de risco dos exportadores, conforme estabelecido pela OIE e legislação brasileira (BRASIL, 2008).

Com isso foi possível detectar grupos formados por tipos específicos de mercadorias por país exportador que podem ser considerados de risco. A análise foi desenvolvida qualitativamente, de forma dicotômica (risco presente/ risco ausente), sem atribuição de notas aos riscos detectados (OIE, 2010a).

\section{RESULTADOS}

As importações que representaram potencial de introdução do agente da EEB no período de 2002 a 2009 foram definidas considerando a classificação de risco para EEB da OIE e a incidência da doença nos países exportadores (OIE, 2010b).

Os dados foram alocados em importações de bovinos vivos (Tabela 1) e de produtos destinados à alimentação animal (Tabela 2), alimentação humana 
(Tabela 3) e de produtos para uso farmacêutico (Tabela 4).

Considerando os períodos recomendados de análise de importações estabelecidos pela OIE de oito anos para produtos de origem bovina para alimentação animal e de sete anos para importação de produtos bovinos para outras finalidades (OIE, 2011), a Figura 1 apresenta a variação dos volumes importados no período de 2002 a 2009.

\section{DISCUSSÃO}

A EEB deve ser considerada como doença de relevância internacional que afeta as relações comerciais entre os países que exportam e importam produtos derivados de bovinos. Diversos países que relataram a doença concluíram que a importação de farinha de carne e ossos e outros produtos bovinos de países contaminados com o agente foi o fator de risco mais relevante (GELDEREN et al., 2003).

A Organização das Nações Unidas para Agricultura e Alimentação (FAO), a Organização Mundial da Saúde (OMS) e a Organização Mundial de Saúde Animal estabeleceram diretrizes conjuntas para o controle da EEB, as quais recomendam que, mesmo aqueles países que não detectaram a doença em seus rebanhos, não devem relaxar as medidas cautelares, que visem impedir a introdução do agente da EEB, em especial, no que tange à análise das informações de comércio de mercadorias que de algum modo possam representar risco (WILSON et al., 2001).

Na Tabela 1 estão demonstradas as importações de bovinos vivos realizadas pelo Brasil e que representam risco. No total, foram importados 476 animais, sendo que os $23(4,8 \%)$ animais oriundos do Canadá foram cadastrados no Sistema Brasileiro de Identificação e Certificação de Origem Bovina e Bubalina (SISBOV) e, conforme a legislação brasileira, não podem ser abatidos para consumo ou para alimentação animal (BRASIL, 2003). Não estão disponíveis informações sobre sexo e prole destes animais e, apesar do risco de transmissão materna permanecer controverso (RIDLEY; BAKER, 1995), esta hipótese deveria ser levada em consideração (OIE, 2011).

Por outro lado, dos 453 (95,2\%) animais importados dos EUA no período analisado, dois não foram rastreados (BRASIL, 2009). Todos estes animais foram importados em 2003, portanto, dois anos antes do primeiro diagnóstico de casos autóctones da doença nos EUA. Considerando o tempo médio de incubação da doença de quatro anos, estes dois casos de animais não rastreados devem ser considerados como risco potencial de introdução do agente da EEB, embora a baixa incidência da doença nos EUA $(0,02$ casos/ milhão de bovinos com mais de 24 meses) (OIE, 2010b) permita reduzir o risco de difusão destasimportações.
Os dados das mercadorias descritas nas Tabelas 2, 3 e 4 são compostos por 11 grupos país-produto. No que se refere aos tipos de mercadorias identificados, foi considerada na análise de risco que a síntese da proteína priônica de membrana celular de conformação normal $\left(\mathrm{PrP}^{\mathrm{c}}\right)$ está descrita em diversos tecidos em bovinos, embora em quantidades diferentes e com predomínio no SNC (Peralta; Eyestone, 2009) e que se presume que a conversão da $\mathrm{PrP}^{\mathrm{c}}$ em proteína priônica de membrana celular alterada conformacionalmente $\left(\mathrm{PrPs}^{\mathrm{sc}}\right)$ não ocorre em todos os tecidos, corroborando com as incógnitas persistentes sobre a forma de conversão destas moléculas (IwATA et al, 2006). Para fins metodológicos, como apresentado anteriormente, apenas aquelas mercadorias que, segundo o Código Sanitário dos Animais Terrestres, não representam potencial infeccioso (como leite e sangue) não foram avaliadas (OIE, 2011).

Sob o aspecto da origem das mercadorias, as importações dos Estados Unidos são as mais relevantes e compõem 8 dos 11 grupos identificados, representando $99,55 \%$ do volume total importado. O risco identificado nos oito grupos de mercadorias provenientes dos Estados Unidos deve-se a um mesmo fator: a identificação de dois casos autóctones da EEB no país, um em 2005 e outro em 2006. Desta forma, as exportações deste país entre 2002 e 2004 foram consideradas, sob análise retrospectiva, como de risco potencial para a EEB, devido ao longo período de incubação da doença.

Estas mercadorias importadas dos Estados Unidos de 2002 a 2004 constituem um grupo bastante diversificado e devem ser analisadas separadamente, entretanto, cabe para todas elas a consideração de que o índice de incidência anual da EEB, conforme mencionado anteriormente, foi infimamente baixo nos EUA (0,02 casos/milhão de bovinos com mais de 24 meses) nos anos de 2005 e 2006 (OIE, 2010b) e que o programa de vigilância intensificado neste país não pôde detectar nenhum outro caso. Ainda assim, o segundo caso detectado foi atribuído às alterações pontuais do códon 211 do gene responsável pela codificação do príon, ou seja, um caso de EEB atípico, do tipo $\mathrm{H}$, para o qual a comunidade científica não identificou fatores de risco associados, indicando tratar-se de caso esporádico da doença (Nicholson et al., 2008). Sendo assim, a probabilidade de contaminação das mercadorias exportadas pelos EUA para o Brasil foi extremamente baixa.

Os alimentos destinados a cães e gatos representaram $81,09 \%$ do volume identificado importado dos EUA. O uso de fontes proteicas de origem animal, incluindo farinha de carne ossos, para alimentação de animais domésticos é frequente no Brasil, bem como em outros países e considerado como fonte adequada para suprir as necessidades nutricionais destas espécies (CARCiOfi et al., 2006). Portanto, é 
bastante adequado considerar que os alimentos importados para cães e gatos dos Estados Unidos de 2002 a 2004 pudessem conter farinha de carne e ossos de bovinos, pois as informações disponíveis não tornam possível afirmar com certeza a composição destas mercadorias. A finalidade da importação e o preço relativamente alto das mercadorias indicam que é muito baixo o risco destes produtos terem sido fornecidos para bovinos no Brasil.
Dentre os grupos identificados nas Tabelas 2, 3 e 4, observa-se que o grupo da farinha de miúdos e torresmos provenientes dos EUA de 2002 a 2004 representa o segundo em volume importado (743.250 kg, 8,80\% das mercadorias provenientes dos EUA). Os dados disponíveis não permitem identificar as espécies animais que compõe a mercadoria, nem identificar quais espécies animais a consumiram.

Tabela 1 - Importações brasileiras de bovinos que representaram risco para EEB de 2003 a 2009.

\begin{tabular}{llcr}
\hline Importações & Observação & 2003 & $2004-2009$ \\
\hline Importação de bovinos do Canadá & Todos os animais foram rastreados (BRASIL, 2009) & 23 & 0 \\
Importação dos EUA de Bovinos & 2 Animais dos 453 importados não foram rastreados & 453 & 0 \\
\hline Total (unidades) & (BRAL, 2009) & 476 bovinos & 0 \\
\hline
\end{tabular}

Tabela 2 - Importações brasileiras de mercadorias destinadas à alimentação animal que representaram risco para EEB de 2002 a 2009.

\begin{tabular}{lcccc}
\hline Importações & 2002 & 2003 & 2004 & $2005-2009$ \\
\hline Importação dos EUA de farinhas de miúdos e torresmos ${ }^{1,2}$ & 52.000 & 138.250 & 553.000 & $*$ \\
Importação dos EUA de alimentos de cães e gatos ${ }^{1,2}$ & 5.032 .352 & 1.601 .361 & 213.147 & $*$ \\
Importação da Malásia de alimentos completos para outras espécies ${ }^{1,3}$ & 17.323 & 18.715 & 0 & $*$ \\
Importação dos EUA de alimentos completos para outras espécies ${ }^{1,2}$ & 87.533 & 46.619 & 67.033 & $*$ \\
\hline Total & 5.189 .208 & 1.804 .945 & 833.180 & 0
\end{tabular}

*As importações realizadas neste período não foram consideradas de risco para esta mercadoria devido às exigências legais para importações vigentes à época.

${ }^{1} \mathrm{O}$ nível de detalhamento não permite identificar a(s) espécie(s) de origem ou que compõe a mercadoria.

${ }^{2} \mathrm{O}$ maior risco foi identificado no período de 2002 a 2004. Após este período, a importação desta mercadoria de origem bovina desde o EUA foi proibida.

${ }^{3} \mathrm{O}$ maior risco foi identificado no período de 2002 e 2003. Após este período, a importação desta mercadoria de origem bovina da Malásia foi proibida.

Tabela 3 - Importações brasileiras de mercadorias destinadas à alimentação humana que representaram risco para EEB de 2003 a 2009.

\begin{tabular}{lcccc}
\hline Importações & 2003 & 2004 & 2005 & $2006-2009$ \\
\hline $\begin{array}{l}\text { Importação da Espanha de preparações alimentícias e conservas de origem } \\
\text { bovina }\end{array}$ & 0 & 0 & 1 & 0 \\
Importação dos EUA de carnes de bovinos salgadas & 8.243 & 0 & 0 & 0 \\
Importação da Itália de carnes de bovinos salgadas & 0 & 0 & 1.600 & 0 \\
Importação dos EUA de Carne bovina congelada não desossada & 1.989 & 0 & 0 & 0 \\
Importação dos EUA de miúdos comestíveis & 146.637 & 0 & 0 & 0 \\
\hline Total & 156.869 & 0 & 1.601 & 0 \\
\hline
\end{tabular}

Tabela 4 - Importações brasileiras de mercadorias destinadas a uso farmacêutico que representaram risco para EEB de 2003 a 2009.

\begin{tabular}{|c|c|c|c|}
\hline Importações & 2003 & 2004 & 2005-2009 \\
\hline Importação dos EUA de glândulas de origem animal para fins farmacêuticos ${ }^{1}$ & 266.018 & 191.701 & * \\
\hline Importação dos EUA de pâncreas bovino para uso farmacêutico & 37.194 & 0 & 0 \\
\hline Total & 303.212 & 191.701 & 0 \\
\hline
\end{tabular}

*As importações realizadas neste período não foram consideradas de risco para esta mercadoria devido às exigências legais para importações vigentes à época.

${ }^{1} \mathrm{O}$ nível de detalhamento não permite identificar a(s) espécie(s) importada(s). 
Volume de Importaçôes de Risco para EEB Efetuadas pelo Brasil de 2002 a $2009(\mathrm{Kg})$

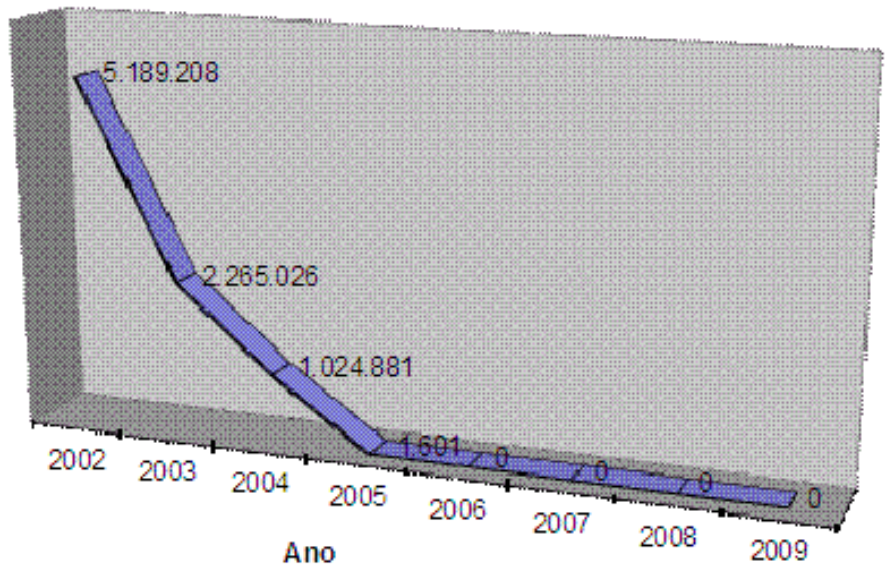

Fig. 1 - Volume de importações brasileiras de mercadorias de risco para EEB de 2002 a 2009.

Dequalquer modo, este grupo soma-se às importações de alimentos completos para outras espécies que não cães e gatos $(201.185 \mathrm{~kg}$ ou 2,38\% das mercadorias norte-americanas) como os mais relevantes no que tange à possibilidade de terem sido fornecidos intencional ou acidentalmente aos bovinos. Embora no período da avaliação houvesse restrição legal ao uso de proteínas de origem animal na alimentação de ruminantes (BRASIL, 2001a), dados do Ministério da Agricultura, Pecuária e Abastecimento revelam que desde 2001 têm sido detectados níveis significativos de proteína de origem animal em alimentos para ruminantes, tanto nas indústrias processadoras como no campo (BRASIL, 2009). Corroboram neste sentido dados de análise de risco conduzida nos EUA em 2003 e que estabeleceram a probabilidade de contaminação cruzada de alimentos para bovinos nos EUA era de $14 \%$ e $25 \%$, no cenário otimista e pessimista, respectivamente (COHEN, 2006).

Outros três grupos de importações dos EUA referem-se às mercadorias destinadas à alimentação humana: carnes de bovinos salgadas, carnes de bovinos congeladas não desossadas e miúdos comestíveis, que juntos representam 1,85\% do volume importado e que, apesar do risco de difusão identificado, constituem risco mínimo na etapa de avaliação de exposição dos indivíduos susceptíveis, devido à baixa probabilidade de terem sido fornecidos para bovinos. De toda a forma, controles de rastreabilidade são desejáveis para estas mercadorias, de modo a garantir a destinação e uso adotados.

$\mathrm{Da}$ mesma forma, os dois últimos grupos de importações dos EUA referem-se a produtos para fins farmacêuticos (Tabela 4): pâncreas bovino e outras glândulas de origem animal. Tanto o pâncreas como as demais glândulas de bovinos fazem parte do grupo de tecidos que representam risco baixo ou não avaliado em testes de veiculação do agente da EEB (OIE, 2011), portanto, não estão nem entre os produtos derivados de bovinos considerados de risco nulo (como sangue e leite), nem entre os tecidos considerados como de risco específico (medula e encéfalo, por exemplo). De qualquer modo, existe relato da presença da proteína $\mathrm{PrP}^{\mathrm{c}}$ nas Ilhotas de Langerhans do pâncreas (PerAlta; Eyestone, 2009) implicando assim em potencial infeccioso. Sobre o grupo das outras glândulas de origem animal, cabe esclarecer que o volume descrito na Tabela 4 refere-se às glândulas originárias de várias espécies animais, sendo provável que glândulas bovinas componham o grupo.

Ainda nestas mesmas tabelas são apresentados dados que mostram que em 2005 foram importados produtos alimentícios derivados de bovinos (conserva e carne salgada) de países que haviam registrado casos de EEB. A Espanha registrou 515 casos de 2000 a 2004 e a Itália 122 casos no mesmo período (OIE, 2010b). O risco das importações identificadas foi mais evidenciado ao considerar que desde 2001, conforme a legislação brasileira, estas mercadorias estão proibidas de serem internalizadas no Brasil (BRASIL, 2001a). Mais especificamente, Espanha e Itália foram classificadas pelas normas brasileiras como países de risco para EEB em 2004, portanto, antes das referidas importações (BRASIL, 2004a). Estas importações são relevantes como fatores de risco de difusão da doença, apesar da finalidade de uso, além de representarem flagrante descumprimento das normas de importação. Especificamente no caso da importação da Espanha, a pequena quantidade importada $(1 \mathrm{~kg})$ diminui o risco específico drasticamente, pois, de acordo com a OIE, o volume im- 
portado deve ser levado em conta na análise de risco e o aumento do volume eleva proporcionalmente o risco (OIE, 2011).

Do volume total de importações de risco listadas nas Tabelas 2, 3 e 4, a parcela de 0,42\% corresponde à importação de alimentos completos para animais (excluindo cães e gatos) da Malásia que, devido à falta de dados disponibilizados à OIE, foi classificada como país de risco desconhecido, sendo esta considerada a pior classificação possível, sob o ponto vista epidemiológico, para EEB (OIE, 2010b). O volume importado deste país foi de $333.068 \mathrm{~kg}$ (Tabela 2) e deve ser analisado sob o aspecto das diferentes normas vigentes à época das importações. Sendo assim, em 2002 e 2003 foram importados 36.038 kg quando estava vigente a Instrução Normativa 15 de 2001 do MAPA (BRASIL, 2001b), a qual estabelecia que a restrição de importação de produtos de origem bovina deveria ser aplicada apenas aos países que haviam registrado casos da doença. Assim, é possível supor que as importações deste período foram as de maior risco, pois possuem potencial para veicular o agente da EEB.

Por outro lado, as importações de alimentos completos para alimentação animal da Malásia a partir de 2005, que corresponderam a $297.030 \mathrm{~kg}$, não representam risco, pois supostamente não possuíam materiais de origem bovina relacionados à EEB já que, a partir desta data, o Brasil passou a realizar classificação de risco a qual enquadrou a Malásia como país exportador de risco para a EEB (BRASIL, 2004a; BRASIL, 2004b). Este fato demonstra as vantagens de submeter as importações à análise de risco em substituição da análise exclusiva da situação epidemiológica oficial do país exportador.

Sob o ponto de vista mais amplo de classificação de risco do Brasil, a partir de 2006 não foi possível detectar qualquer risco de difusão do agente no território nacional (Fig. 1). Assim, é possível afirmar que em 2013 (caso sejam mantidos os controles legais), completar-se-á um período integral de 8 anos sem fatores de risco no que se refere à entrada potencial do agente da EEB. Porém, cabe afirmar que mesmo a importação de mercadoria consideradas de risco não constitui impeditivo absoluto a uma melhor classificação de risco, caso possa ser demonstrado controle da destinação e uso destas importações (OIE, 2011).

De qualquer forma, evidencia-se a limitação de informações disponíveis para subsidiar a adoção de medidas de controle oficiais e análise de risco: os dados compilados pelo MDIC estão agrupados em conveniência aos interesses fiscais e comerciais e não aos interesses sanitários. Neste sentido, seria útil para o controle de uma gama de doenças relevantes no comércio internacional de animais e produtos derivados, a formação de um banco de dados que contemple a composição das importações, em especial a(s) espécie(s) de origem das mercadorias e maior detalhamento da destinação da mercadoria.

\section{CONCLUSÃO}

Durante a análise dos fatores de difusão do agente da EEB no território brasileiro no período de 2002 a 2009 foram identificadas importações relevantes. As quantidades importadas diminuíram progressivamente no período até 2005 e, finalmente, em 2006 não foram registradas importações com significado de risco. Onível de detalhamento dos dados disponíveis é baixo, gerando assim volumes de mercadorias de risco maiores do que os reais. A classificação de risco para EEB dos países membros da OIE leva em consideração período retrospectivo de até oito anos e, neste caso, a importação de mercadorias dos EUA, Itália, Espanha, Canadá e Malásia pelo Brasil demonstram potencial de risco de introdução do agente no país, o qual, entretanto, deve ser considerado como extremamente baixo dada a análise de incidência da EEB nos países exportadores e/ou a finalidade de uso das importações. Os dados apresentados e analisados indicam que as medidas de controle sobre importações (mitigação de risco), caso mantidas, reduzirão o risco de introdução do agente da EEB ao menor nível possível em 2013, quando em um período de oito anos (2006-2013) estima-se que não deverão ser detectadas importações de risco. Para compreensão completa dos fatores relacionados à EEB, deve ser conduzida análise de risco dos fatores de exposição dos suscetíveis.

\section{REFERÊNCIAS}

BRASIL. Ministério da Agricultura Pecuária e Abastecimento. Instrução Normativa n. 6, de 1 de fevereiro de 2001. Diário Oficial [da] República Federativa do Brasil, Brasília, DF, 16 jun. 2001a. Seção 1, p.5.

BRASIL Ministério da Agricultura Pecuária e Abastecimento. Instrução Normativa n. 15, de 17 de julho de 2001. Diário Oficial [da] República Federativa do Brasil, Brasília, DF, 19 jul. 2001b. Seção 1, p.2.

BRASIL. Ministério da Agricultura Pecuária e Abastecimento. Instrução Normativa n. 18, de 15 de dezembro de 2003. Diário Oficial [da] República Federativa do Brasil, Brasília, DF, 24 dez. 2003. Seção 1, p.21. Proibe o abate de ovinos e bubalinos importados...

BRASIL. Ministério da Agricultura Pecuária e Abastecimento. Instrução Normativa n. 25, de 06 de abril de 2004. Diário Oficial [da] República Federativa do Brasil, Brasília, DF, 8 abr. 2004a. Seção 1, p.1. 
BRASIL Ministério da Agricultura Pecuária e Abastecimento. Instrução Normativa n. 7, de 17 de março de 2004. Diário Oficial [da] República Federativa do Brasil, Brasília, DF, 18 mar. 2004b. Seção 1, p.5. Proibe a importação de ruminantes seus produtos e...

BRASIL. Ministério da Agricultura Pecuária e Abastecimento. Instrução Normativa n. 49, de 15 de setembro de 2008. Diário Oficial [da] República Federativa do Brasil, Brasília, DF, 16 set. 2008. Seção 1, p.8. Estabelece categorias de risco para encefalopatias espongiformes bovina...

BRASIL. Ministério da Agricultura Pecuária e Abastecimento. Secretaria de Defesa Agropecuária. Questionário para reconhecimento de situação sanitária referente à Encefalopatia Espongiforme Bovina. Brasília, 2009.

BRASIL Ministério do Desenvolvimento, Indústria e Comércio Exterior. Sistema de análise das informações de comércio exterior via internet (ALICE-WEB). Brasília: MDIC, 1989-2010. Disponível em: <http:/ / aliceweb. desenvolvimento.gov.br/>. Acesso em: 19 jan. 2011.

CARCIOFI, A.C.; PONTIERI, R.; FERREIRA, C.F.; PRADA, F. Avaliação de dietas com diferentes fontes proteicas para cães adultos. Revista Brasileira de Zootecnia, v.35, n.3, p.754-760, 2006.

COHEN, J.T. Harvard model of bovine spongiform encephalopathy implications of importing cattle over 30 months of age from Canada. Center for the Evaluation of Value and Risk Institute for Clinical Research and Health Policy Studies Tufts New England Medical Center, 2006. 37f.

GELDEREN, C.; GIMENO, E.J.; SCHUDEL, A.A. Bovine spongiform encephalopathy in South America: a regional preventive approach. Revue Scientifique et Technique, v.22, n.1, p.227-236, 2003.

IWATA, N.; SATO, Y.; HIGUCHI, Y.; NOHTOMI, K.; NAGATA, N.; HASEGAWA, H.; TOBIUME, M.; NAKAMURA, Y.; HAGIWARA, K.; FURUOKA, H.; HORIUCHI, M.; YAMAKAWA, Y.; SATA, T. Distribution of PrPsc in Cattle with Bovine Spongiform Encephalopathy Slaughtered at Abattoirs in Japan. Japanese Journal of Infectious Diseases, v.59, p.100-107, 2006.

NICHOLSON, E.M.; BRUNELLE, B.W.; RICHT, J.A.; KEHRLI, M.E.; GREENLEE, J.J. (2008) Identification of a Heritable Polymorphism in Bovine PRNP Associated with Genetic Transmissible Spongiform Encephalopathy: Evidence of Heritable BSE. PLoS ONE v.3, n.8, e2912 Disponível em <http:/ / www.plosone.org/arti-
cle/info\%3Adoi\%2F10.1371\%2Fjournal.pone.0002912>. Acesso em: 12 ago. 2010.

OIE - ORGANISATION MONDIALE DE LA SANTE

ANIMALE. Handbook on Import Risk Analysis for Animals and Animal Products. Paris: OIE, 2010a. 88p.

OIE - WORLD ORGANIZATION FOR ANIMAL

HEALTH. Number of reported cases of bovine spongiform encephalopathy (BSE) in farmed cattle worldwide. Paris: OIE, 2010b. Disponível em: <http://www.oie.int/eng/ info/en_esbmonde.htm> Acesso em: 2 nov. 2010.

OIE - ORGANIZACIÓN MUNDIAL DE SANIDAD

ANIMAL. Encefalopatia Espongiforme Bovina. In: . Código Sanitário para los Animales Terrestres.

18.ed. Paris: OIE, 2011. p.601-633.

PERALTA, O.A.; EYESTONE, W.H. Quantitative and qualitative analysis of cellular prion protein $\left(\mathrm{PrP}^{\mathrm{c}}\right)$ expression in bovine somatic tissues. Prion, v.3, n.3, p.161-170, 2009.

PRINCE, M.J.; BAILEY, J.A.; BARROWMAN, P.R.; BISHOP, K.J.; CAMPBELL, G.R.; WOOD, J.M. Bovine spongiform encephalopathy. Revue Scientifique et Technique, v.22, n.1, p.37-60, 2003.

RIDLEY, R.M.; BAKER, H.F. The myth maternal transmission of spongiform encephalopathy. British Medical Journal, v.311, p.1071-1075, 1995.

WELLS, G.A.H.; SCOTT, A.C.; JOHNSON, C.T. A novel progressive spongiform encephalopathy in cattle. Veterinary Record, v.121, n.18, p.419-420, 1987.

WILESMITH, J.W.; WELLS, G.A.H.; CRANWELL, M.P.; RYAN J.B.M. Bovine spongiform encephalopathy: epidemiological studies. Veterinary Record, v.123, n.25, p.638-644, 1988.

WILL, R.G.; IRONSIDE, W. A new variant of Creutzfeldt-Jakob disease in the UK. Lancet, v.347, p.92925, 1996.

WILSON, K.; HÉBERT, P.C.; LAUPACIS, A.; DORNAN, C.; RICKETTS, M.; AHMAD, N.; GRAHAM, I. A policy analysis of major decisions relating to CJD and the blood supply. Canadian Medical Association Journal, v.165, n.1, p.59-65, 2001.

Recebido em 15/8/11

Aceito em 27/10/12 